\title{
Fiscalização dos Recursos da Merenda Escolar nas Escolas Públicas do Município de Satuba em Alagoas, desde o inicio até 2016
}

\author{
Rosana Maria Lima Albuquerque Sales ${ }^{1}$; Graciela Fanego ${ }^{2}$
}

\begin{abstract}
Resumo: A investigação analisa como acontece a fiscalização dos recursos que são repassados através do Programa Nacional de Alimentação Escolar para o município de Satuba /AL, com a finalidade de compreender o contexto que permeia a fiscalização dos recursos de uma política de alimentação escolar no Brasil; o procedimento de descentralização e as vulnerabilidades que permeiam a gestão do programa; analisar a analogia do Fundo Nacional de Desenvolvimento da Educação com os diretores de escolas frente à gestão do Programa no contexto de uma Política de Estado; e propõe uma ferramenta pedagógica que estimule a transparência e o controle social na execução dos recursos do Programa Nacional de Alimentação Escolar A pesquisa traça o percurso histórico da política de alimentação escolar e dos institutos subsidiários do Ministério da Educação, responsáveis pela execução da alimentação escolar, descreve o processo de descentralização da política de financiamento do Programa Nacional de Alimentação Escolar, visando altercar a relevância do planejamento na política de alimentação escolar e o papel dos agentes educacionais, sua função e a visão dos órgãos de fiscalização e controle face à execução e gestão do programa nos municípios, a atuação dos conselhos de alimentação escolar, bem como a análise propositiva acerca do processo de descentralização, da gestão e do controle social da política de alimentação escolar. O percurso metodológico da pesquisa utilizada é qualitativo, foram pesquisadas duas escolas públicas, uma municipal e outra estadual, os instrumentos utilizados foram: entrevistas semiestruturadas, levantamento e análise documental. O trabalho aponta como resultados que o Programa Nacional de Alimentação Escolar tem avançado em termos de financiamento e gestão, embora haja desafios que ainda precisam ser superados para garantir mais qualidade à alimentação escolar, como: aumento do valor per capita, fortalecimento da participação cidadã; capacitação técnica dos gestores do programa nos municípios; modernização do processo de gestão, tanto no âmbito do Fundo Nacional Desenvolvimento Nacional quanto no dos estados e, principalmente, nos municípios.
\end{abstract}

Palavras-chave: Alimentação Escolar. Fiscalização dos Recursos. Descentralização. Gestão. Controle Social.

\section{Supervision of School Lunch Resources in the Public Schools of the City of Satuba in Alagoas, from the beginning until 2016}

\begin{abstract}
The investigation examines how the monitoring of the resources that are passed through the National School Feeding Program for the municipality of Satuba / AL, with the purpose of understanding the context that permeates the control of the resources of a school feeding policy in Brazil, The decentralization procedure and the vulnerabilities that permeate the management of the program; To analyze the analogy of the National Fund for the Development of Education with school principals regarding the management of the Program in the context of a State Policy; And proposes a pedagogical tool that stimulates transparency and social control in the execution of the resources of the National School Feeding Program The research traces the historical course of school feeding policy and of the subsidiary institutes of the Ministry of Education responsible for the execution of school feeding, Describes the decentralization process of the financing policy of the National School Feeding Program, aiming at altering the relevance of planning in school feeding policy and the role of educational agents, their role and the vision of the inspection and control bodies in the execution and management Of the program in the municipalities, the activities of the school feeding councils, as well as the proactive analysis about the decentralization process,
\end{abstract}

\footnotetext{
${ }^{1}$ Maestría en Gobierno y Gerencia Pública. Universidad Americana. Facultad de Posgrado. Asuncion - PY.

${ }^{2}$ Universidad Americana. Facultad de Posgrado. Asuncion - PY.
} 
the management and social control of school feeding policy. The methodological course of the research used is qualitative, two public schools were surveyed, one municipal and the other state, the instruments used were: semistructured interviews, survey and documentary analysis. The results show that the National School Feeding Program has advanced in terms of financing and management, although there are challenges that still need to be overcome in order to guarantee better quality of school feeding, such as: increasing per capita value, strengthening citizen participation; Technical training of program managers in municipalities; Modernization of the management process, both within the scope of the National Development National Fund and in the states and, especially, in the municipalities.

Keywords: School Feeding. Supervision of Resources. Decentralization. Management. Social Control

\section{Introdução}

O Programa Nacional de Alimentação Escolar (PNAE) oferece alimentação escolar e ações de educação alimentar e nutricional a estudantes de todas as etapas da educação básica pública. O governo federal repassa a estados, municípios e escolas federais, valores financeiros de caráter suplementar efetuados em 10 parcelas mensais (de fevereiro a novembro) para a cobertura de 200 dias letivos, conforme o número de matriculados em cada rede de ensino.

São atendidos pelo programa os alunos de toda a educação básica (educação infantil, ensino fundamental, ensino médio e educação de jovens e adultos) matriculados em escolas públicas, filantrópicas e em entidades comunitárias (conveniadas com o poder público). Vale destacar que o orçamento do PNAE beneficia milhões de estudantes brasileiros, como prevê o artigo 208, incisos IV e VII, da Constituição Federal. Pelo volume de recursos do PNAE e da dimensão geográfica do Brasil, se torna inevitável e necessária à preocupação com a fiscalização e monitoramento do Programa Nacional de alimentação Escolar, com a conclusão dos resultados esperados e não esperados impetrados e com a prestação de contas dos gestores, transformada em uma constante inquietação nas atividades de governo, uma vez que o propósito da avaliação é direcionar os tomadores de decisão, orientando-os no tocante à continuidade, necessidade de ajuste ou até suspensão caso o mesmo não utilize adequadamente os recursos no Programa Nacional de Alimentação Escolar.

Observando-se a grandiosidade da política nacional de alimentação escolar em presença a sociedade e os órgãos de controle interno e externo do governo federal, evidenciam-se distorções e desestruturas na execução do programa, os quais sinalizam a existência de problemas de gestão nesse programa.

Deve ao FNDE e ao Conselho de Alimentação Escolar (CAE) monitorar a execução do programa e, anos demais Órgãos internos e controles externos SEJAM OU, faça Tribunal de Contas da União (TCU) dá Controladoria Geral da União (CGU) e Ministério Público fazer. No entanto, apesar do 
trabalho de muitos órgãos ocorrem ainda irregularidades que precisam ser superadas, por isso a investigação tem como base algumas escolas de uma cidade do interior de Alagoas.

De uma análise crítica da realidade e as políticas públicas especificamente as do Governo Federal se observa que há muitas questões que carecem ser esclarecidas, no que tange a gestão e controle dos recursos alimentares para os alunos. Daí a necessidade de avaliar, compreender e explicar os entraves que permeiam a execução do programa, para superar as dificuldades estratégicas, técnicas e operacionais do programa de alimentação escolar.

Os objetivos deste estudo foram: a) Identificar como se dá a fiscalização dos recursos da merenda escolar nas escolas públicas do município de Satuba, dentro de uma perspectiva de política pública do governo federal através da gestão e do controle social do PNAE; b) Precisar quais são, no contexto histórico nacional, os fatores que propiciaram a construção de uma política de alimentação escolar; c) Estabelecer qual é o processo de descentralização do PNAE; d) Analisar quais são, no contexto histórico nacional, os fatores que propiciaram a construção de uma política de alimentação escolar; e) Propor as ferramentas pedagógica/critérios que estimulem a transparência e o controle social na execução do Programa Nacional de Alimentação Escolar (PNAE).

\section{Programa Nacional de Alimentação Escolar (PNAE)}

Um dos maiores e mais antigos programas na área de alimentação escolar do mundo, o Programa Nacional de Alimentação Escolar (PNAE), representa a maior e mais abrangente experiência em programas de alimentação e nutrição na América do Sul, destaca-se pela inovação, pela grandiosidade e por ser o único a atender a todo território Nacional, pois abrange todos os estudantes matriculados nas escolas públicas de toda a educação básica, da creche ao ensino médio. O Controle Social é de suma importância através da participação da comunidade educativa no sentido de acompanhar e de se fazer presente na execução e fiscalizar os resultados desse programa.

Contudo, vale ressaltar que programa possui caráter suplementar, adicional, marcado no inciso VII do art. 208 da Constituição Federal de 1988 e também no inciso VII do art. $4^{\circ}$ da Lei de Diretrizes e Bases da Educação (LDB) de 1996: "atendimento ao educando no ensino fundamental através e programas suplementares de material didático-escolar, transporte, alimentação e assistência à saúde" (BRASIL, 1996). O FNDE transfere os recursos financeiros oriundos do Tesouro Nacional, assegurados no Orçamento da União, às entidades executoras (estados, Distrito Federal e municípios) em contas exclusivas abertas pela própria Autarquia - sem obrigação de celebração de convênio, ajuste, combinação, contrato ou qualquer outro instrumento. 
Para conduzir os recursos, o dinheiro repassado pelo FNDE, as entidades executoras têm autonomia e competência para concretizar a complementação dos recursos para melhorar a qualidade e quantidade do cardápio escolar, em conformidade com a Constituição de 1988. Essa transferência é realizada em 10 (dez) parcelas mensais - cada parcela equivale a 20 (vinte) dias de aula -, a partir do mês.

Do início do ano letivo no intuito de cobrir os 200 dias letivos obrigatórios, como determina MEC. 70\% desses recursos são designados à aquisição de produtos alimentícios básicos, fundamentais para a alimentação escolar dos estudantes.

Existe um calculo que serve de parâmetro para que aconteça o repasse. Cálculo:

$T R=$ Número de alunos $x$ Número de dias $x$ Valor per capita, em que TR é o total de recursos a serem recebidos.

Para que a merenda escolar chegue a seu destino final, nas escolas, faz-se necessário que as instituições estejam cadastradas no censo escolar realizado pelo INEP.

O Programa Nacional de Alimentação Escolar (PNAE) investiu no ano de 2016 R \$ 3,4 bilhões investidos em alimentação em escolas públicas, filantrópicas e comunitárias.

Com a Lei $\mathrm{n}^{\circ} 11.947$, de 16/6/2009, 30\% desse valor era para ser investido na compra direta de produtos da agricultura familiar, de agricultores do próprio município, incentivando e dando condições dos agricultores locais comercializarem seus plantios.

\section{Ferramentas pedagógica/critérios para estimular a transparência e o controle social na execução do Programa Nacional de Alimentação Escolar (PNAE)}

A escola estrutura-se e se organiza em suas dimensões administrativa e pedagógica através de processos da gestão democrática fundamentada nos princípios de descentralização, autonomia e participação. Nesse contexto, vale ressaltar que a Gestão Democrática na escola é uma realidade, mas que, infelizmente, ainda se observa a falta de integração entre os segmentos que compõem a comunidade escolar, resultando no enfraquecimento do trabalho e da gestão democrática.

Há, portanto, a ausência de um planejamento efetivamente participativo e compartilhado devido, sobretudo, às constantes dificuldades em reunir a comunidade escolar, que se expressa pela incompatibilidade de horários de alguns professores, pela ausência de compromisso social, político e pedagógico, por parte de alguns, e/ou iniciativa para com o planejamento e participação nas atividades globais da escola.

Desse modo, a escola precisa compreender e vivenciar em suas ações cotidianas que gestão democrática implica não apenas intenção, mas também método para sua efetivação. São vários os 
obstáculos, como se apontou anteriormente, que a escola enfrenta a esse respeito. Entende-se, como destaca Gadotti (2000), que a maioria dos problemas apontados se deve: A pouca experiência democrática; À mentalidade que atribui aos técnicos (e apenas a estes) a capacidade de governar e que o povo é incapaz de exercer o poder; À própria estrutura verticalizada dos sistemas educacionais; Ao autoritarismo que, historicamente, tem impregnado o etos educacional; Ao tipo de liderança que tradicionalmente domina a atividade política no campo educacional.

Para enfrentar essas dificuldades, é preciso de acordo com Gadotti (2000): O desenvolvimento de uma consciência crítica; $\mathrm{O}$ envolvimento das pessoas - comunidade interna e externa à escola; Participação das várias esferas do governo; Autonomia, responsabilidade e criatividade como processo e como produto do projeto.

Enfim, é preciso compromisso político e engajamento dos professores, dirigentes, pais, alunos e funcionários para construir a própria identidade da escola como instituição social, assumir compromissos, para criar um futuro melhor do que o presente.

Nesse cenário as instâncias colegiadas têm um papel fundamental como se destaca a seguir:

O Conselho Escolar é um órgão de representação da comunidade escolar. Trata-se de uma instância colegiada que deve ser composta por representantes dos segmentos da comunidade escolar. O Conselho Escolar deve constituir-se num espaço de discussão educativa e seus desdobramentos na prática político-pedagógica da escola. Nesse sentido, como aponta Navarro (2004), o Conselho Escolar tem as seguintes funções:

a) Consultivas: quando têm um caráter de assessoramento, analisando as questões encaminhadas pelos diversos segmentos da escola e apresentando sugestões ou soluções, que poderão ser ou não ser acatadas pelas direções das unidades escolares.

b) Fiscais (acompanhamento e avaliação): quando acompanham a execução das ações pedagógicas, administrativas e financeiras, avaliando e garantindo o cumprimento das normas da escola e a qualidade social do cotidiano escolar.

c) Mobilizadoras: quando promovem a participação, de forma integrada, dos segmentos representativos da escola e da comunidade local em diversas atividades, contribuindo, assim, para a efetivação da democracia participativa e para a melhoria da qualidade social da educação.

Cabe ao Conselho Escolar avaliar o projeto político-pedagógico propor alterações e implementá-lo. O Conselho Escolar tem um importante papel no debate sobre os principais problemas da escola e suas possíveis soluções.

De modo geral, serão atribuições do Conselho Escolar: Elaborar o regimento Interno do Conselho Escolar; Coordenar o processo de discussão, elaboração ou alteração do Regimento Escolar; Convocar assembleias-gerais da comunidade escolar ou de seus segmentos; Garantir a participação das comunidades escolar e local na definição do projeto político-pedagógico da unidade escolar; Promover 
relações pedagógicas que favoreçam o respeito ao saber do estudante e valorize a cultura da comunidade local; Propor e coordenar alterações curriculares da unidade escolar, respeitada a legislação vigente, a partir da análise, entre outros aspectos, do aproveitamento significativo do tempo e dos espaços pedagógicos na escola; Propor e coordenar discussões junto aos seguimentos e votar às alterações metodológicas, didáticas e administrativas na escola, respeitada a legislação vigente; Participar da elaboração do calendário, no que competir à unidade escolar, observada a legislação vigente; Acompanhar a evolução dos indicadores educacionais (abandono escolar, aprovação, aprendizagem, entre outros), propondo, quando se fizerem necessárias, intervenções pedagógicas e/ou medidas socioeducativas, visando à melhoria da qualidade social da educação escolar; Elaborar o plano de formação continuada dos conselheiros escolares, visando ampliar a qualificação de sua atuação; Aprovar o plano administrativo anual, elaborado pela direção da escola, sobre a programação e a aplicação de recursos financeiros, promovendo alterações, se for o caso; Fiscalizar a gestão democrática, pedagógica e financeira da unidade escolar; Promover relações de cooperação e intercâmbio com outros Conselhos Escolares.

Para o exercício dessas e de outras atribuições que forem definidas segundo a autonomia da escola, é indispensável considerar que a qualidade que se pretende atingir é a qualidade social, ou seja, a realização de um trabalho escolar que represente, no cotidiano vivido, crescimento intelectual, afetivo, político e social dos envolvidos - tendo como horizonte a transformação da realidade brasileira -, o que não pode ser avaliado/medido apenas por meio de estatísticas e índices oficiais.

A composição do Conselho Escolar deve estar de acordo com a legislação vigente e suas funções regulamentadas pelo Poder Público e se movimentar mediante Estatuto próprio. Devem participar do Conselho, com direito a voz e voto, todos que fazem parte da comunidade escolar e forem eleitos representantes pelos seus pares.

O Conselho de Classe é mais um dos mecanismos de participação da comunidade na gestão e no processo de ensino-aprendizagem desenvolvido na unidade escolar. Constitui-se numa das instâncias de vital importância num processo de gestão democrática, pois "guarda em si a possibilidade de articular os diversos segmentos da escola e tem por objetivo de estudo o processo de ensino, que é o eixo central em torno do qual se desenvolve o processo de trabalho escolar" (DALBEN, 1995, p. 16).

Além dos professores, devem participar do Conselho de Classe o diretor (geral e adjunto), o orientador educacional, o coordenador pedagógico e, quando necessário, representantes de alunos e pais. Compete ao Conselho de Classe: Analisar dados referentes ao desenvolvimento do ensinoaprendizagem, da relação professor/aluno, ao relacionamento entre os próprios alunos e outros assuntos específicos da turma; Sugerir medidas pedagógicas a serem adotadas, visando superar as dificuldades encontradas; Deliberar a respeito da promoção final dos alunos. 
As deliberações quanto a promoção final dos alunos pautar-se-á em critérios baseados no desempenho escolar do aluno, quais sejam: Parecer do professor da disciplina; Frequência às aulas; Evolução do desempenho escolar; Participação em atividades de recuperação oferecidas; Envolvimento e interesse com os estudos e as atividades desenvolvidas pela escola; Pareceres da coordenação e direção; Outros critérios que venham ser sugeridos e aprovados pelo Conselho.

As reuniões do Conselho de Classe serão por nível de ensino presidido pela direção, incumbindo-lhe: Presidir as atividades do Conselho; Convocar reuniões (ordinária e extraordinária); Indicar membro do conselho para secretariar as reuniões; Coordenar as ações visando sanar os problemas pedagógicos constatados.

São incumbências dos membros do Conselho de Classe: Aprovar as alterações nas normas de funcionamento do Conselho; Opinar sobre o rendimento escolar, assiduidade e disciplina do aluno, apresentando sugestões para seu aprimoramento; Divulgar as decisões do Conselho, quando necessário; Apreciar assuntos de natureza sigilosa, por solicitação de qualquer membro do Conselho; Opinar sobre assuntos referentes à promoção, à recuperação e á reprovação do aluno; Lavrar atas de reuniões, quando indicado pelo diretor; Comparecer às reuniões extraordinárias do Conselho quando necessário.

As reuniões do Conselho serão sistematizadas e divididas em cinco momentos: Primeiro Momento: Pré-Conselho; Segundo Momento: Análise individual do aluno/professor; Terceiro Momento: Análise individual de cada aluno pelo grupo de professores; Quarto Momento: presentação e análise dos dados coletados no pré-conselho com a presença dos setores envolvidos, com líderes ou vice-líderes de turma; Quinto Momento: Avaliação dos encaminhamentos apurados; A coordenação pedagógica juntamente com o corpo docente e direção deverá construir coletivamente regulamento para o funcionamento satisfatório e sistematizado do Conselho fundamentado no Regimento Escolar e na filosofia educacional da escola.

Além das instâncias colegiadas acima citadas, a escola conta ainda com os seguintes atores, serviços e setores na sua organização formal:

A Escola Estadual Professor Manoel Gentil Do Vale Bentes é mantida com recursos oriundos do Fundo Nacional de Desenvolvimento da Educação (FNDE) autarquia do MEC (Ministério da Educação), a saber:

I) O Programa Dinheiro Direto na Escola (PDDE) este recurso é transferido à conta da escola, em parcela única anual, destinam-se à cobertura das despesas nas seguintes categorias econômicas:

Recurso de Custeio: são aqueles destinados à aquisição de materiais de consumo e à contratação de serviços para funcionamento da escola, quais sejam:

- Manutenção, conservação e pequenos reparos da unidade escolar;

- Aquisição de material de consumo necessário ao funcionamento da escola; 
- Implementação do projeto pedagógico, avaliação da aprendizagem e desenvolvimento de atividades educacionais.

É vedado o uso dos recursos do PDDE na compra de bens e na contratação de serviços que resultem em benefícios individuais e que não atendam ao interesse coletivo, não sendo permitida a aquisição de materiais para distribuição e doação ao aluno.

a) Recurso de capital: são aqueles destinados a cobrir despesas com aquisição de material permanente para as escolas, que resultem em reposição ou elevação patrimonial, a saber:

- Aquisição de material permanente.

II) Plano de Desenvolvimento da Escola (PDE) - O PDE é um processo gerencial em que a escola desenvolve um planejamento estratégico com a participação da comunidade. O processo começa com uma análise do desempenho da instituição, seus processos, seus pontos fortes e fracos, suas condições de funcionamento e seus resultados. A partir dessa análise se projeta o futuro, definindo aonde se quer chegar e que estratégias adotar para alcançar seus objetivos. A partir da construção do PDE a escola define um Projeto de Melhoria/PME a cada ano detalhando seu plano.

III) Programa Nacional de Alimentação Escolar (PNAE) - recurso é transferido à conta da escola em várias parcelas durante o ano letivo, destinam-se à aquisição de gêneros alimentícios. É conhecida a extrema importância da alimentação na vida dos alunos. Com vínculos estreitos ao aproveitamento no processo de aprendizagem, a qualidade dos alimentos consumidos pelos estudantes é determinante no rendimento escolar e, em muitos casos, na sua própria permanência na escola.

A diretriz da inclusão da educação alimentar e nutricional no processo de ensino e aprendizagem, perpassando pelo currículo escolar, foi assinalada no art. $2^{\circ}$, inciso II, da Lei 11.947/09.

Devesse propiciar que os dados que atingem a alimentação escolar estejam disponíveis a todos, sem que seja necessária identificação ou registro.

\section{Marco Metodológico}

Trata-se de uma pesquisa quantiqualitativa, descritiva e explicativa. O universo de estudo foram as duas escolas, Escola Estadual Manoel Gentil do Valle Bentes e Escola Municipal Hígia Ramalho C. Vasconcelos, da zona urbana do Município de Satuba, Alagoas, Nordeste do Brasil. As Escolas atendem a um público de estudantes que recebem alimentação escolar com recursos do governo federal.

Elegeu-se o lócus da pesquisa acerca da política de alimentação escolar considerando os seguintes critérios: a) o estado de Alagoas recebe recursos em caráter suplementar para a execução do PNAE e a complementação da União, ensejando a fiscalização dos recursos pelo Tribunal de Contas da 
União (TCU) e pela Controladoria Geral da União (CGU); b) ocupa a $27^{\circ}$ posição no ranking do Índice de Desenvolvimento Humano (IDH).

A prestação de contas do PNAE realiza-se por meio do Demonstrativo Sintético Anual e da Execução Físico-Financeira. A secretaria de educação do estado ou do município envia a prestação de contas ao Conselho de Alimentação Escolar (CAE) até 15 de fevereiro do ano subsequente ao do recebimento. Depois de avaliar a documentação, o CAE prepara parecer e o remete, junto com a prestação de contas e todos os comprovantes de despensas, para o FNDE até o dia 31 de março (FNDE, 2012). Assim, foi analisada a situação das prestações de contas do município selecionado a fim de verificar os recursos e o desempenho dos conselhos.

Para a realização deste trabalho utilizou-se o método de pesquisa qualitativa. A opção por esse tipo de pesquisa deu-se em virtude do trabalho com dados retirados do contexto real mais especificamente de duas escolas no município de Satuba do estado de Alagoas. Compreende-se que a pesquisa qualitativa é relevante porque, em termos metodológicos, ela propicia um olhar reflexivo sobre as práticas de distribuição da alimentação escolar nesse município.

Os dados foram colhidos no primeiro semestre de 2016. Para a realização da referida pesquisa observou-se duas escolas públicas, as quais serviram para análise comparação dos dados.

As escolas pesquisadas foram escolhidas por dois motivos:

a) Por serem escolas que atendem ao grupo de crianças que recebem alimentação escolar;

b) Por serem escolas públicas. As referidas instituições são da rede pública estadual e municipal da cidade de Satuba, no estado de Alagoas.

Para o levantamento dos dados e posterior análise recorreu-se às seguintes técnicas/instrumentos:

Levantamento documental a respeito dos conceitos e teorias sobre a alimentação escolar; políticas de alimentação escolar da Educação/MEC; Conselho Estadual de Educação e conselho municipal de educação e órgãos fiscalizadores. Essa técnica possibilitou a análise de materiais elaborados especificamente sobre o tema. Moreira e Caleffe (1996, p. 20), afirmam que o objetivo primordial dessa técnica é: "colocar o pesquisador em contato direto com tudo o que já foi produzido na área em questão";

Entrevista semiestruturada aplicada às nutricionistas no âmbito municipal e estadual, às gestoras e técnicas das secretarias e a comunidade escolar. A escolha desse tipo de entrevista deve-se à preferência por um ambiente no qual o entrevistado não se sinta pressionado ao responder aos questionamentos levantados, possibilitando, assim, um diálogo no qual o sujeito investigado coloque-se de forma espontânea. Segundo Moreira e Caleffe (2006, p. 168), com esta técnica: “o pesquisador pode 
elaborar uma lista de perguntas ou tópicos que deseja explorar, mas deve estar preparado para que os entrevistados falem à vontade".

Com duas nutricionistas, sendo uma do estado e a outra do Município de Satuba, ela explanaram suas dificuldades e limitações, colocando que nas respectivas escolas não falta merenda, contudo existem muitos entraves e que a fiscalização ainda é muito primária, através do questionamento, foram visualizadas as possíveis conclusões das problemáticas.

Projetos Político-Pedagógicos das Escolas (PPP), Regimento escolar e atas do conselho, foram utilizados para a elaboração da caracterização dos bairros e das escolas pesquisadas, as normas estabelecidas dentro de cada instituição e no município.

O Município de Satuba não tem conselho direcionado para cada escola, pois ainda não foi descentralizado, o Conselho de Alimentação Escolar é municipal. Tudo relacionado às compras é concentrado na própria Secretaria de Educação do município. A alimentação é comprada pelo conselho formado pela Secretaria o CRE, este faz as compras e depois distribui para as escolas de acordo com o desenvolvimento de cada escola e com seu tipo de funcionamento.

O Programa Municipal de Alimentação Escolar de Satuba é gerenciado e operacionalizado pela Secretaria Municipal de Educação, por intermédio de um convênio entre a Prefeitura e a empresa.

A Secretaria municipal possui uma nutricionista que elabora o cardápio respeitando a faixa etária e as especificidades de estudantes de cada escola. São entregues nas escolas os alimentos juntamente aos cardápios prontos. As merendeiras de cada escola preparam a alimentação da instituição que é distribuída diariamente.

As compras da merenda são feitas em setor de licitação na prefeitura, em consonância com a secretaria de educação. A escola lista sua necessidade e a encaminha para o setor de licitação que funciona no prédio da prefeitura, o responsável pela licitação. As licitações são realizadas e a empresa vencedora começa o fornecimento dos alimentos.

Os recursos são divididos em parcelas durante o ano para o município e, então, o Município destina para a merenda. Este pedido é comprado quinzenalmente e outros pedidos são comprados mensalmente de acordo com a necessidade da escola e do tipo de alimento, perecível e não perecível. Esse recurso chega à conta do município e, só então, é pago à empresa que ganhou a licitação. Tal pagamento é dividido por ano, se o município precisar de mais alimentação, será complementado também por licitação que será feita de novo em função da necessidade.

A alimentação é descentralizada, por isso é aberto um processo de licitação com chamada pública e publicada no diário oficial, na qual são analisadas três planilhas. A empresa que ofertar melhor preço em sua cotação será a que o estado fechará acordo para o fornecimento da alimentação escolar. 
A maioria das escolas está tomando como norte de compra de alimentação escolar a licitação, que tem suas especificidades na Constituição Federal, como especificada no primeiro capítulo desta pesquisa.

\section{Análise dos dados}

Foram utilizados sete perguntas para coleta com os conselheiros das duas escolas do município de Satuba. Três delas serviram para análise sobre o programa de alimentação escolar.

Pergunta: O que falta para melhorar a fiscalização do CAE para o recurso da merenda escolar na cidade de Satuba?

Gestora da Escola Estadual - O repasse para as escolas de forma direta, os recursos vêm para as secretarias e são redestribuídos.

Gestora Escola Municipal - O acesso direto aos recursos. Facilitaria muito.

Fonte: elaborado pela autora

As escolas têm o mesmo ponto de vista em relação aos recursos, a descentralização seria uma forma de agilizar e poder escolher os alimentos, como também facilitaria o controle dos recursos.

Pergunta: Como é feita a comunicação do FNDE com as unidades escolares e com os conselhos de alimentação escolar?

Gestora Escola Estadual - O Contato do FNDE é com a secretaria, existe um departamento que tem o contato e controle.

Gestora Escola Municipal - Não temos contato direto, tivemos visitas, mas o contato é feito com as técnicas da secretaria e repassado para a escola.

Fonte: elaborado pela autora

Ao se analisar as falas acima, observa-se que as gestoras, tanto a da escola estadual quanto da municipal, não têm acesso direto aos recursos destinados à alimentação escolar. Todo o contato é feito por meio das secretarias que adquirem e repassam os alimentos para as escolas.

Outro ponto relevante é a ineficiência da fiscalização de forma efetiva nos municípios. As gestoras enfatizam a falta de recursos humanos para a demanda.

Pergunta: Como tem sido a atuação dos conselhos de alimentação escolar no Programa?

Gestora Escola Estadual - O conselho tenta, se reúne e faz o que está ao alcance.

Gestora Escola Municipal- Quando necessário o conselho se reúne e discute o que é necessário.

Os órgãos federais também não tem como fiscalizar todos os municípios. O que está ao alcance da escola e da secretaria é feito.

Fonte: elaborado pela autora 
Os Conselhos de Alimentação Escolar (CAE) são fundamentais para garantir que o Programa Nacional de Alimentação Escolar (PNAE) funcione a contento, contudo eles tentam, ainda de forma muito fraca, fazer uma fiscalização eficiente e real, com uma maior participação nos diversos seguimentos para deliberar fatos que são levados para discussão e aprovação.

Em visita ao Tribunal de Contas de Alagoas, situado em Maceió, a princípio, tem-se receio de falar sobre a fiscalização do Programa Nacional de Alimentação Escolar (PNAE), mas um funcionário da instituição mencionou a precariedade de recursos humanos e estruturais para uma efetiva fiscalização dos 102 municípios alagoanos. Essa estrutura ineficaz estabelece uma relação de poder entre os que estão à frente da compra, distribuição e prestação de contas das escolas e da merenda escolar, demonstrando uma fragilidade na fiscalização levando a uma ineficiência e até as irregularidades na utilização dos recursos destinados à alimentação escolar.

Em fala, um dos conselheiros do seguimento pais afirmou que não consegue ir a todas às reuniões por estar sempre trabalhando e reconhece que erra nesse aspecto e por esse motivo, diversas vezes, desconhece o conteúdo que foi tratado nas reuniões do CAE, mas deposita confiança na diretora e na coordenação da escola, por conhecer o trabalho das mesmas. Observou-se que durante as reuniões são deliberados assuntos importantes que precisam ser compartilhados posteriormente. No entanto, na reunião seguinte, dias ou até mesmo meses depois, faz-se apenas a leitura da ata, não focando para os assuntos que foram tratados anteriormente.

É notório perceber que os membros do conselho da escola municipal são pessoas conhecidas e/ou que têm um bom relacionamento com os gestores, secretário de educação ou até com o próprio prefeito, contudo os membros do Conselho de Alimentação Escolar estadual tem outra estrutura, visto que diversifica os membros, diante da dimensão estadual. No âmbito municipal as aprovações e deliberações tornam-se mais simples, no estadual existe uma maior articulação e, portanto um cuidado do gestor em relação às reuniões e deliberações que são definidas pelo conselho.

Com a pesquisa, percebeu-se o quanto é frágil a fiscalização desses recursos. A descentralização ainda não se dá de forma integral. Seria possível garantir uma boa aplicação desses recursos com uma fiscalização séria por parte de órgãos federais, o que não acontece devido à falta de recursos humanos, de pessoas qualificadas para atuar nos municípios e de uma estrutura para o deslocamento dessas pessoas. A comunidade escolar e o conselho escolar são agentes que deveriam mobilizar essa discussão nos órgãos destinados a essa fiscalização.

Nos questionários passados a comunidade escolar, tanto da escola municipal e estadual e os demais consultados, nasceram dentro do âmbito dos usuários dos serviços do PNAE, direta ou indiretamente, essas pessoas envolvidas na logística, manutenção conhece a realidade da fiscalização da merenda escolar, pois vivenciam diariamente com essas demandas. A definição de critérios segundo os 
quais foram selecionados os sujeitos que fizeram parte do universo da investigação foi analisada com cautela, pois interfere diretamente na qualidade das informações.

O processo de seleção dos sujeitos da população estatística das entrevistas aconteceu em primeiro lugar pelos objetivos da pesquisa, partindo desse modo os entrevistados foram propostos entre as pessoas que efetivamente puderam contribuir no sentido do tema escolhido da identificação de pessoas envolvidas com a merenda escolar, as escolas visitadas, o CAE e diversas visitas com base no julgamento do entrevistador e seu conhecimento da população, selecionando os respondentes com mais chances de auferir a informação necessária. Esta seleção foi feita considerando que a amostra poderia oferecer as contribuições solicitadas, desse modo participaram os seguintes sujeitos: 2 Diretores; 3 Coordenadores; 2 Nutricionistas; 8 Professores; 4 merendeiras; 2 porteiros; 6 alunos; 6 Pais; 9 conselheiros de alimentação escolar; 8 pessoas da comunidade que cerca a escola.

Gráfico 1 - Enquete: Você fiscaliza a merenda escolar?

\section{VOCÊ FISCALIZA A MERENDA ESCOLAR?}

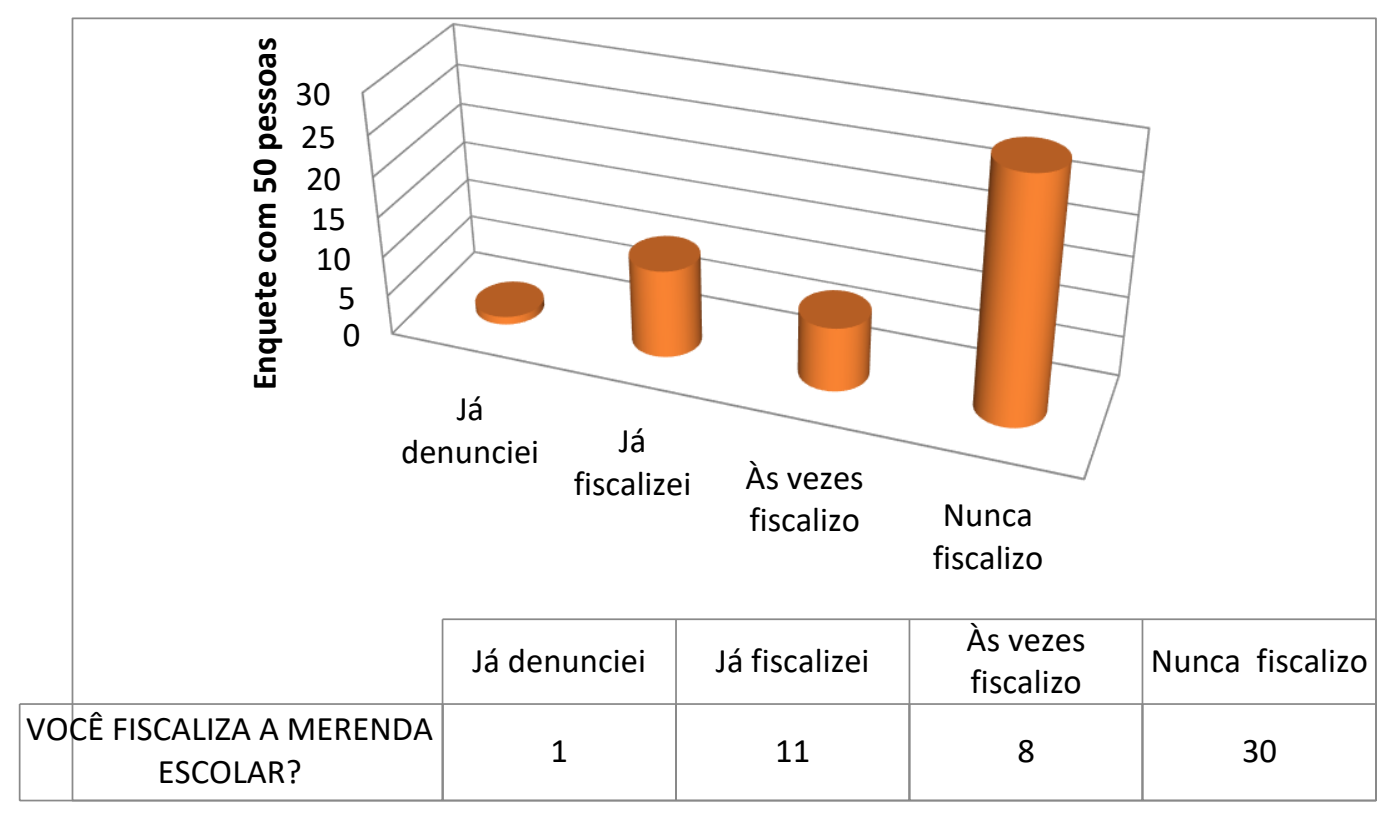

Fonte: elaborado pela autora

O Conselho de Alimentação Escolar é um canal da área de merenda escolar que mais se aproxima da comunidade, uma vez que de todos os membros titulares somente um é apontado pelo prefeito. Os demais membros do conselho, que são seis, são preenchidos por progenitores de alunos, de entidades civis e dos educadores, alunos ou trabalhadores da educação (em geral, são os docentes). Os membros do conselho são elegíveis pelos segmentos aos quais fazem parte, por meio de assembleias 
exclusivas, assumindo um mandato de quatro anos, desempenhado de forma não remunerada, sendo considerada de relevante interesse público e, os interessados em exercê-la. Para o cumprimento das obrigatoriedades, a Secretaria de Educação precisa colocar a disposição uma completa base imprescindível, assim como, espaço apropriado para as assembleias (mensais) e condução para o deslocamento dos componentes do conselho.

A função de Conselheiro de Alimentação Escolar é muito importante, suas atribuições e responsabilidades são inúmeras, é preciso muitas ações voltadas para o monitoramento do PNAE, conseguindo bons resultados na fiscalização do programa, afim de um acompanhamento regular através de visitas in loco, que possibilite que os mesmos interroguem os alunos, observando se eles estão contentados com a alimentação ofertada pela escola e analisem outras irregularidades que prejudiquem o fluxo do Programa Nacional de Alimentação Escolar. É essencial que o conselho informe à Secretaria de Educação sobre os problemas identificados no momento das visitas e, posteriormente, averigue as resoluções tomadas em relação às mesmas. Se ocorrer das contas não estiverem corretas e não forem aprovadas pelo Conselho de Alimentação Escolar, FNDE pode acatar a decisão do conselho e fazer uma abertura de processo interno para averiguar as irregularidades e haver a suspensão do repasse por tempo indeterminado.

O Que Falta Para Melhorar A Fiscalização do Cae para o recurso da Merenda Escolar na Cidade de Satuba?

Gráfico 2 - Conselho Municipal de Alimentação Escolar

\title{
Conselho Municipal de Alimentação Escolar
}

\author{
- Melhor articulação com gestor \\ - Transporte para deslocamento para visitas in lócus \\ Incentivos finaceiros \\ Espaço físico para reuniões
}

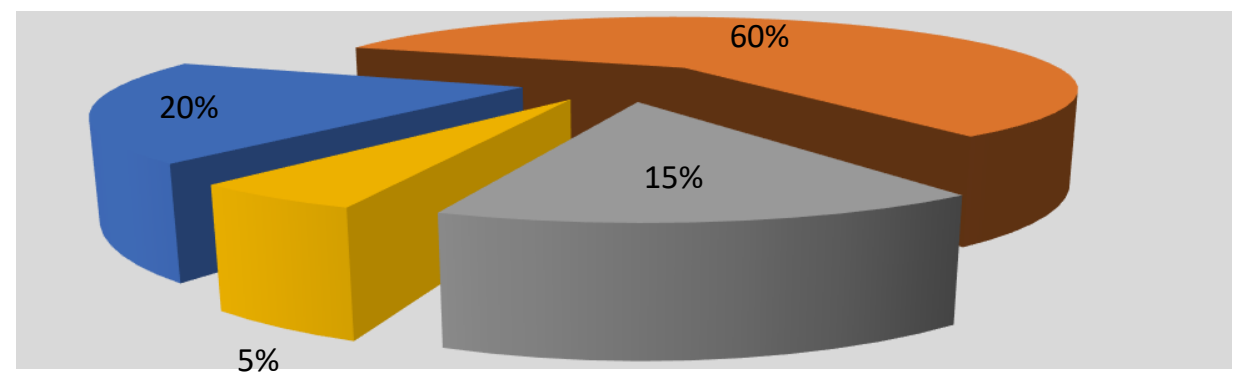

Fonte: elaborado pela autora 
Gráfico 3 - Conselho Estadual de Alimentação Escolar

\section{Conselho Estadual de Alimentação Escolar}

Um único conselho para o Estado Todo $\square$ Transporte para visitas in lócus

$\square$ Falta de apoio financeiro

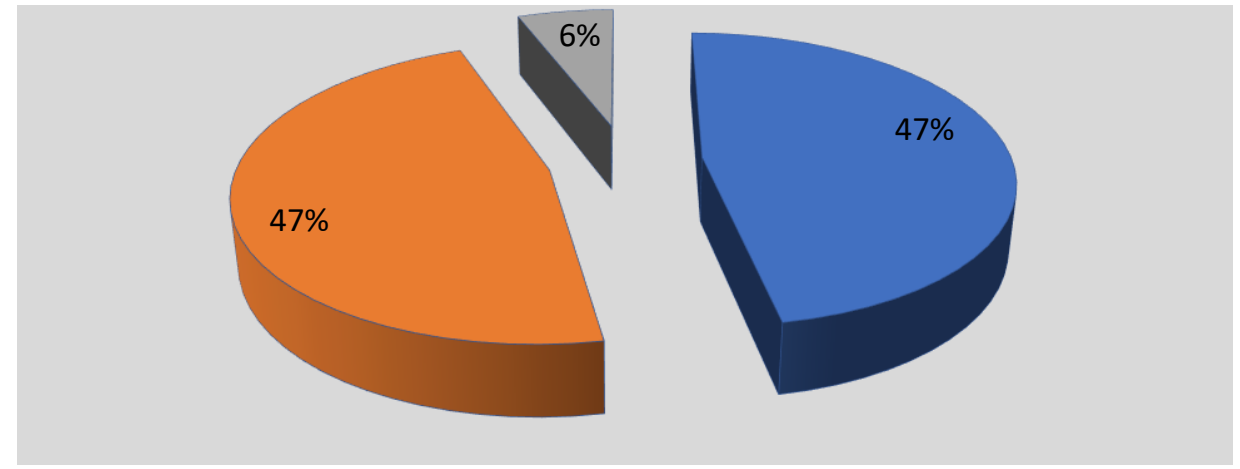

Fonte: elaborado pela autora

Quais são as maiores dificuldades para a execução do trabalho do Nutricionista?

Gráfico 4 - Nutricionista do Município

\section{Escola Municipal Hígia R. de Castro Vasconcelos}

- Valor do repasse baixo por criança Demora do fornecedor

1 nutricionita só paraa o município

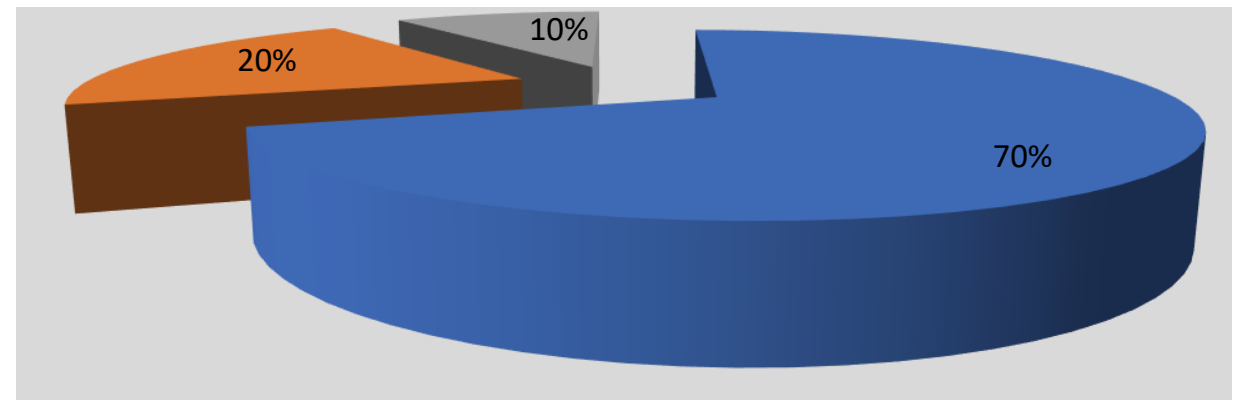

Fonte: elaborado pela autora 
Gráfico 5 - Nutricionista do estado

\section{Escola Estadual Manuel Gentil do Valle Bentes}

\footnotetext{
- Apenas 1 nutricionista para todo o estado Não há visitas in locus

$\square$ Não conhecer a necessidade de cada escola $\square$ Cardápio unificado
}

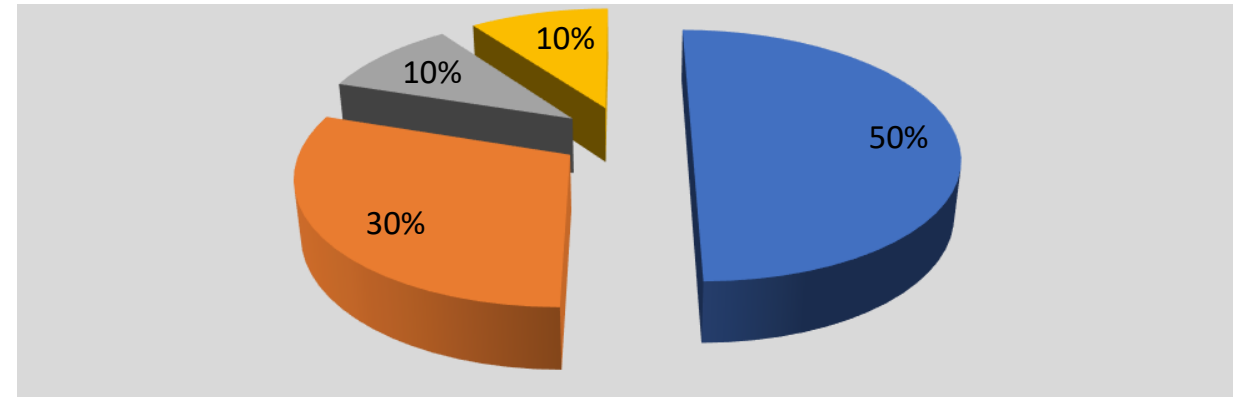

Fonte: elaborado pela autora

Um grande desafio para o CAE é que a maior parte da comunidade ignora a existência do colegiado, e se faz necessária divulgação das ações do CAE, uma a própria da tática para fortalecê-lo é tornar pública a sua atuação, suas atribuições e importância para o bom funcionamento do programa no município.

Constatasse que o PNAE cresceu em todo Brasil e também em Satuba, com ele a agricultura familiar foi beneficiada, melhorou a qualidade da alimentação e com ela a aprendizagem. A pesquisa aponta esses caminhos para uma real efetivação desses recursos em prol dos alunos e da comunidade. 


\section{Quantas vezes você questionou a escola sobre a merenda escolar?}

Gráfico 6 - Gráfico com a Escola Municipal Hígia Ramalho

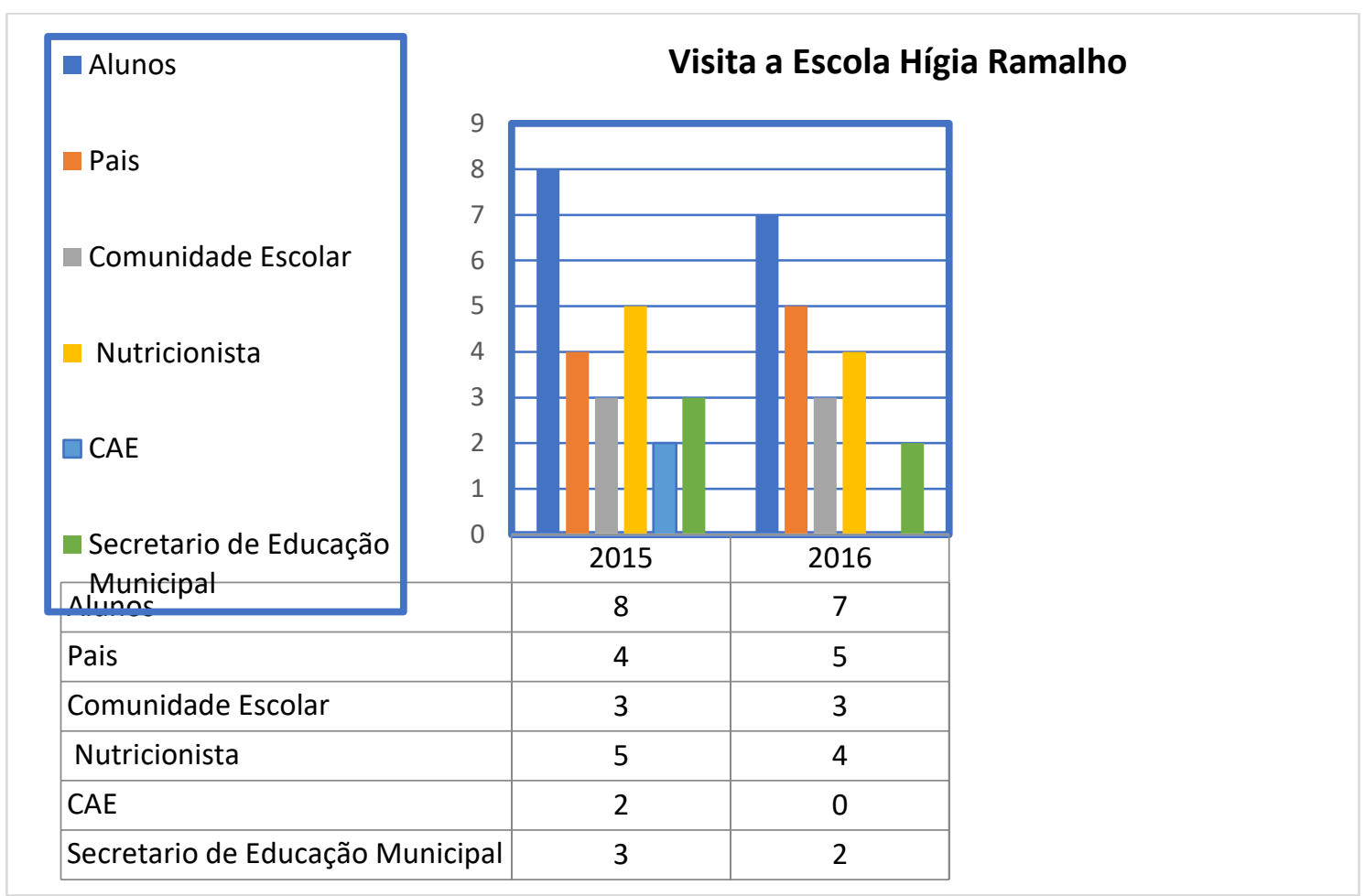

Fonte: Escola Municipal Hígia Ramalho

Através das informações levantadas com a comunidade Escolar, procurou-se explicitar a realidade situacional em relação a fiscalização da merenda escolar, por meio de informações in loco, com base nos questionários destinados a 50 pessoas da comunidade escolar como um todo, observaramse os seguintes dados, a saber:

Os pesquisados foram escolhidos, dentre as comunidades escolares da Escola Municipal Hígia Ramalho de Castro Vasconcelos e da Escola Manoel Gentil do Valle Bentes, partindo do pressuposto que o tamanho da amostra foi o tamanho ideal, a amostra foi composta de 50 sujeitos ( 29 da escola municipal e 21 da escola estadual), divididos em três grupos (Servidores das escolas, alunos e o CAE).

A investigação foi feita com 18 visitas in loco, entre elas, 09 (nove) visitas às escola municipal e estadual, 02 (duas) visitas em órgãos fiscalizadores do município de Rio Largo, onde fica a gerência de Educação do estado que coordena a Escola Estadual de Satuba, 2 (duas) visitas as nutricionistas, 04 (quatro) visitas aos Conselhos de Alimentação Escolar (CAE) e 1 (uma) visita ao setor de licitação do município, que são responsáveis por essas fiscalizações e secretarias de educação municipal e estadual. 
A parcela pesquisada foi um subconjunto da comunidade escolar que efetivamente existe, seria impraticável entrevistar todos os ambientes de uma comunidade contendo duas escolas, pois levaria muito tempo para findar o trabalho e até mesmo seria financeiramente inexequível, dessa forma, o número de entrevistados corresponde a uma quantidade de pessoas que se dispuseram a responder a investigação, visto que, a Escola Municipal Hígia Ramalho de Castro Vasconcelos é pequena totalizando 17 funcionários e 44 alunos, sendo em um bairro periférico da cidade, a Escola Estadual Manoel Gentil do Valle Bentes tem 43 funcionários e 276 alunos nos três turnos, sendo pesquisados 29 da municipal e 21 da estadual, diante da disponibilidade em participar do momento da entrevista.

\section{Conclusão}

Os dados colhidos durante a pesquisa aconteceram em 09 (nove) visitas às escolas do município de Satuba - Alagoas - Brasil, 02 (duas) visitas em órgãos fiscalizadores do município de Rio Largo, onde fica a gerência de Educação do estado que coordena a Escola Estadual de Satuba, 2 (duas) visitas a nutricionistas, 04 (quatro) visitas aos Conselhos de Alimentação Escolar (CAE) e 1 (uma) visita ao setor de licitação do município, que são responsáveis por essas fiscalizações e secretarias de educação municipal e estadual do município pesquisados, para situar, relembrar o real significado das políticas públicas e dos recursos para a alimentação escolar, sendo ela centralizada, descentralizada, apontaram a fragilidade na fiscalização desses recursos.

O cenário político tem avançado no que concerne a garantir essa conquista que é a descentralização da alimentação escolar. Precisa-se cobrar dos municípios a fiscalização, uma contrapartida que não está acontecendo realmente, como deveria ser.

Observe-se o que tem sido colocado em âmbito nacional. A cartilha elaborada pelo apoio Fome Zero - Associação de Apoio a Políticas de Segurança Alimentar 2004 traz todo o processo do repasse dessa verba federal:

Recursos destinados à merenda escolar Anualmente, com base no censo escolar, o Governo Federal repassa recursos financeiros do Fundo Nacional de Desenvolvimento da Educação (FNDE), assegurados no Orçamento da União, às chamadas Entidades Executoras (EEs, que são basicamente os estados, Distrito Federal e municípios5 ). Esses recursos são transferidos diretamente a contas correntes específicas, abertas pelo pró- prio FNDE, sem a necessidade de celebração de convênio, ajuste, acordo, contrato ou qualquer outro instrumento. A transferência se faz em dez parcelas mensais, a partir do mês de fevereiro de cada ano, para a cobertura de 200 dias letivos (para as creches a cobertura é de 250 dias). As Entidades Executoras têm autonomia para administrar os recursos, sendo que $70 \%$ do total recebido do FNDE deve ser aplicado em produtos básicos6. A lei determina que a merenda atenda a $15 \%$ das necessidades diárias dos alunos beneficiados. Hoje, o Governo Federal repassa 13 centavos por dia e por aluno para a merenda no ensino 
fundamental e 18 centavos no caso de creches. Caso as Entidades Executoras entendam que os recursos repassados pelo FNDE não são suficientes, elas mesmas devem complementá-los, conforme estabelecido na Constituição Federal.(BRASIL, 2004.)

A importância de um órgão fiscalizador como os Conselhos de Alimentação Escolar (CAEs) mostrou-se um avanço no sentido das políticas públicas.

Considerando a composição, atribuições e competências dos CAEs e sua importância para o adequado desenvolvimento do programa de merenda escolar, fica evidente que, para começar a fiscalizar o que está ocorrendo com a merenda escolar no município, o primeiro passo é tomar contato com o respectivo CAE, para ver se ele está funcionando como deve, se os conselheiros estão se reunindo regularmente. Uma boa verificação a fazer é, por exemplo, a da regularidade das reuniões do CAE. A freqüência mais usual é de uma reunião por mês, mas pode variar de acordo com a regulamentação interna. Entretanto, se o CAE se reúne apenas uma vez por ano, e apenas para aprovar a prestação de contas, este é um forte sinal de que o Conselho não é atuante. Infelizmente, o mais comum é que o CAE não funcione adequada e regularmente. Por meio do seu Programa de Sorteios, a Controladoria Geral da União (CGU) constatou que em 49 dos 50 municípios fiscalizados na $4^{\text {a }}$ edição desse Programa, os Conselhos (assim como as demais comissões municipais) não têm atuação efetiva. Em alguns municípios, eles foram constituídos apenas formalmente, mas não desempenham suas atribuições, deixando de realizar reuniões e de fiscalizar a aplicação dos recursos federais. Em um dos casos investigados pela CGU, o Presidente do CAE era também presidente da Comissão Permanente de Licitação da prefeitura, desconhecia qualquer atribuição do CAE, não havia realizado nenhuma reunião com os conselheiros e muito menos efetivava qualquer ação de fiscalização da merenda escolar. Muitas vezes os membros dos CAEs desconhecem suas atribuições e até mesmo quem são os demais membros do Conselho, não visitam as escolas e não dão portanto qualquer tipo de orientação para resolver problemas relativos ao programa da merenda escolar, comprometendo sua boa execução.

Vale ressaltar que modelos de descentralização que se tem hoje no município de Satuba referentes à alimentação escolar não têm a opção para o repasse direto dos recursos financeiros federais, ou seja, do FNDE para escola, como ocorre no Programa Dinheiro Direto na Escola (PDDE). Com a Lei $\mathrm{n}^{\circ}$ 11.947/2009, o FNDE pode repassar os recursos diretamente à UEx em casos nos quais existam irregularidades na execução do programa ou em que os municípios apresentem inadimplência em suas prestações de contas, haja vista o disposto nos artigos 20 e 21 :

Art. 20. Fica o FNDE autorizado a suspender os repasses dos recursos do PNAE quando os Estados, o Distrito Federal ou os Municípios: I - não constituírem o respectivo CAE ou deixarem de efetuar os ajustes necessários, visando ao seu pleno funcionamento; II - não apresentarem a prestação de contas dos recursos anteriormente recebidos para execução do PNAE, na forma e nos prazos estabelecidos pelo Conselho Deliberativo do FNDE; III - cometerem irregularidades na execução do PNAE, na forma estabelecida pelo Conselho Deliberativo do FNDE. § 1o Sem prejuízo do previsto no caput, fica o FNDE autorizado a comunicar eventuais irregularidades na execução do PNAE ao Ministério Público e demais órgãos ou autoridades ligadas ao tema de que trata o Programa. § $20 \mathrm{O}$ restabelecimento do repasse dos recursos financeiros à conta do PNAE ocorrerá na forma definida pelo 
Conselho Deliberativo do FNDE. Art. 21. Ocorrendo a suspensão prevista no art. 20, fica o FNDE autorizado a realizar, em conta específica, o repasse dos recursos equivalentes, pelo prazo de 180 (cento e oitenta) dias, diretamente às unidades executoras (grifos meus), conforme previsto no art. 6 o desta Lei, correspondentes às escolas atingidas, para fornecimento da alimentação escolar, dispensando-se o procedimento licitatório para aquisição emergencial dos gêneros alimentícios, mantidas as demais 96 regras estabelecidas para execução do PNAE, inclusive quanto à prestação de contas. Parágrafo único. A partir da publicação desta Lei, o FNDE terá até 180 (cento e oitenta) dias para regulamentar a matéria de que trata o caput deste artigo (BRASIL, 2009)

(...) existe o artigo 21 na Lei $n^{\circ} 11.947$ (2009) que faculta ao FNDE repassar pras escolas é também faculta, mas por seis meses, então assim, durante seis meses, até ele se regularizar. O problema é de tal ordem, de tanto abertura bancária, de você ter quem vai receber esse recurso, porque o diretor de escola, ele é vinculado à prefeitura e você tá suspendendo o município, não está suspendendo a pessoa física do gestor, do prefeito, entendeu? Então assim, qual a diferença entre penalizar o diretor e penalizar o prefeito, no caso é o município que está assumindo, arcando com a responsabilidade de pagar pelo preço da inadimplência dele. Poderemos passar pras associações de pais e mestres como o PDDE repassa? Poderia, mas quem prestaria conta? Esse é o único problema, você teria de firmar convênio com esse pessoal, pra ele repassar, porque eles são entidades privadas, sem fins lucrativos, mas privadas, a lei permite que você repasse para entidades privadas sem fins lucrativos, mediante convênio, até você firmar o convênio, ele receber, ele viabilizar a compra e ele ofertar, acabou seis meses, esse é um problema de repassar direto pra escola que é diferente do PDDE que a lei permite repassar direto pra escola, onde o diretor ou a associação recebe. No nosso caso, não é permitido você repassar diretamente, somente nesses casos de suspensão e, mesmo assim, com todos os problemas, com todas as burocracias que a lei define, né. A outra questão é que, na grande maioria, a suspensão se dá por ausência de CAE, do Conselho de Alimentação Escolar. (BRASIL, 2009).

As políticas públicas educacionais, o processo de descentralização só existe porque há repasse de verba federal para estados e municípios. Portanto, é nesse espaço e no processo de educação cidadã que cada indivíduo precisa se reconhecer como parte da sociedade e da conjuntura política, econômica e sociocultural, compreender o seu papel como requerente de direitos, cumpridor de deveres e, sobretudo, conceber, reivindicar, fiscalizar e cobrar os recursos públicos como direito comum e que se chegue de forma integral e igualitária para o bem estar das crianças e adolescentes.

Diante disso, cada um dos envolvidos nos conselhos se torna um ator social - gestor, nutricionista, técnica em alimentação escolar, agricultor familiar, conselheiros, secretários, coordenadores, diretores de escola - que poderá transformar o rumo da política de alimentação escolar, avançando em cidadania, em direitos humanos, em melhoria de vida e em educação pública de qualidade, gratuita e humanizada para todos os cantos deste país, com responsabilidade, pautada em um trabalho com excelência, onde prefeitos, secretários, vereadores, ministério público e demais autoridades façam sua parte com consciência, com honestidade, dignidade e respeito pelo povo, agregando melhorias, valores e fomentando a qualidade de vida das pessoas, e consequentemente o desenvolvimento pleno do município. 


\section{Referências}

ALMEIDA, Fernanda Dias. Competências na Constituição de 1988. São Paulo: Atlas, 1991.

AMARAL, Nelson Cardoso. Para compreender o financiamento da educação básica no Brasil. Brasília: Liber livro, 2012.

ARAÚJO, F. A. S. Capitalismo monopolista. 2007. Disponível em: <http://www.marxists.org/portugues/tematica/rev_prob/12/capitalismo.htm>. Acesso em: 11 ago. 2012.

ARRETCHE, Marta. Relações federativas nas políticas sociais.Educ. Soc. Campinas, v. 23, n. 80, setembro/2002. Disponível em: 〈http://www.cedes.unicamp.br>. Acesso em: 30 maio 2013.

BETTO, Frei. A fome como questão política. Estud. av., v. 17, n. 48, pp. 53-61, 2003.

BOBBIO, Norberto. A Era dos Direitos. Rio de Janeiro: Elsevier, 2004.

BITTENCOURT, Marcus Vinícius Corrêa. Manual de Direito Administrativo. São Paulo: Editora Fórum, 2010.

BRASIL. Alimentação Escolar: banco de dados. Disponível em: <http://www.brasil.gov.br/sobre/obrasil/o-brasil-em-numeros-1/educacao/print>. Acesso em: 23 mar. 2012.

Constituição da República Federativa do Brasil. 1988. Disponível em: <http://www.planalto.gov.br/ccivil_03/constituicao/constituicao.htm>. Acesso em: 5 jun. 2012.

Controladoria-Geral da União. Relatório de Fiscalização 01131, $26^{\circ}$ Sorteio do Projeto de Fiscalização a partir de Sorteios Públicos de Unidades Municipais. 2008b. Disponível: <http://portal.tcu.gov.br/educacao-corporativa/relatorios/>. Acesso em: 12 jul. 2012.

Decreto-Lei no 3.689, de 3 de outubro de 1941. Código de Processo Penal. 1941. Disponível em: <http://www.planalto.gov.br/ccivil_03/decreto-lei/Del3689.htm>. Acesso em: 7 jul. 2013.

Decreto $\mathbf{n}^{0}$ 4.177, de 28 de março de 2002. Transfere para a Corregedoria-Geral da União as competências e as unidades administrativas da Casa Civil da Presidência da República e do Ministério da Justiça que especifica e dá outras providências. 2002. Disponível em: <http://www.planalto.gov.br/ccivil_03/decreto/2002/D4177.htm >. Acesso em: 28 jul. 2013.

Decreto $n^{\circ}$ 6.253, de 13 de novembro de 2007. Dispõe sobre o Fundo de Manutenção e Desenvolvimento da Educação Básica e de Valorização dos Profissionais da Educação - FUNDEB, regulamenta a Lei n.11.494, de 20 de junho de 2007, e dá outras providências. 2007b. Disponível em: <http://www.planalto.gov.br/ccivil_03/_ato2007-2010/2007/decreto/d6253.htm>. Acesso em: 12 jul. 2012.

Indicadores demográficos e educacionais -Alagoas. Disponível em: <http://ide.mec.gov.br/2011/estados/relatorio/uf/27>. Acesso em: 10 ago. 2012.

Lei no 11.494, de 20 de junho de 2007. Regulamenta o Fundo de Manutenção e Desenvolvimento da Educação Básica e de Valorização dos Profissionais da Educação - FUNDEB. 2007a. Disponível em: Acesso em: 12 jul. 2012.

Lei no 11.947, de 16 de junho de 2009. Dispõe sobre o atendimento da alimentação escolar e do Programa Dinheiro Direto na Escola aos alunos da educação básica. 2009a. Disponível em: <http://www.fnde.gov.br/pnae/legislacao>. Acesso em: 25 mar. 2012. 
Lei $\mathbf{n}^{0} \mathbf{1 2 . 7 9 8}$ de 4 de abril de 2013. Estima a receita e fixa a despesa da União para o exercício financeiro de 2013. 2013a. Disponível em: <http://www.planalto.gov.br/ccivil_03/_Ato20112014/2013/Lei/L12798.htm>. Acesso em: 22 abr. 2013.

Lei $\mathbf{n}^{\circ}$ 8.913, de 12 de julho de 1994. Dispõe sobre a municipalização da merenda escolar.1994.Disponível em: 〈http://www.planalto.gov.br/ccivil_03/leis/L8913.htm〉. Acesso em: 10 jul. 2012.

Lei no 9.394, de 20 de dezembro de 1996. Lei de Diretrizes e Bases da Educação. 1996a. Disponível em: 〈>. Acesso em: 4 maio 2012.

Lei no 9.424, de 24 de dezembro de 1996. Dispõe sobre o Fundo de Manutenção e Desenvolvimento do Ensino Fundamental e de Valorização do Magistério. 1996b. Disponível em: <http://www.planalto.gov.br/ccivil_03/leis/L9424.htm>. Acesso em: 4 maio 2012.

Medida Provisória no 1.784, de 14 de dezembro de 1998. Dispõe sobre o repasse de recursos financeiros do Programa Nacional de Alimentação Escolar, institui o Programa Dinheiro Direto na Escola, e dá outras providências.1998b. Disponível em: <http://www.planalto.gov.br/ccivil_03/mpv/Antigas/1784.htm>. Acesso em: 12 maio 2012.

Medida Provisória no 2143-31, de 2 de abril de 2001. Altera dispositivos da Lei no 9.649, de 27 de maio de 1998, que dispõe sobre a organização da Presidência da República e dos Ministérios, e dá outras providências. 2001. Disponível em: <https://www.planalto.gov.br/ccivil_03/MPV/ Antigas_2001/214331.htm >. Acesso em: 28 ju.1 2013.

Ministério da Educação. Fundo Nacional de Desenvolvimento da Educação. Secretaria de Educação a Distância. Brasília: MEC, FNDE, SEED, 2009d.

Ministério da Educação. Brasília: Plano de Desenvolvimento do Ensino Fundamental e Valorização do Magistério, 1995.

Relatório de Fiscalização 01548. $31^{\circ}$ Sorteio do Projeto de Fiscalização a partir de Sorteios Públicos de Unidades Municipais. 2010. Disponível: <http://www.cgu.gov.br/assuntos/auditoria-efiscalizacao/programa-de-fiscalizacao-em-entes-federativos/3-ciclo/edicoes-anteriores/municipios/31osorteio>. Acesso em: 25 mar. 2012.

Resolução no 005, de 24 de março de 2006. 2006a. Disponível em: <http://www.fnde.gov.br/ index.php/ae-legislacao>. Acesso em: 25 mar. 2012.

Resolução no 038, de 19 de agosto de 2008. 2009. Disponível em: <http://www.fnde.gov.br/pnae/legislacao〉. Acesso em: 25 mar. 2012.

Resolução no 042, de 10 de agosto de 2009. 2009. Disponívelem: 〈http://www.fnde.gov.br/pnae/legislacao $>$. Acesso em: 25 mar. 2012.

Resolução no 042, de 14 de dezembro de 2006. 2006b. Disponível em: <http://www.fnde.gov.br/ index.php/ae-legislacao>. Acesso em: 25 mar. 2012.

Resolução no 24, de 14 de junho de 2013. Estabelece orientações, critérios e procedimentos para a utilização obrigatória a partir de 2013 do Sistema de Gestão de Conselhos (Sigecon). 2013b. Disponível em: $<$ http://www.fnde.gov.br/fnde/legislacao/resolucoes/item/3512-resolu\%C3\%A7\%C3\%A3o-cd-fnden\%C2\%BA-2-de-18-de-janeiro-de-2012>. Acesso em: 29 jul. 2013. 
Resolução $\mathbf{n}^{\circ}$ 358, de 18 de maio de 2005. Dispõe sobre as atribuições do Nutricionista no âmbito do Programa de Alimentação Escolar (PAE) e dá outras providências. 2005. Disponível em: <http://www.cfn.org.br/novosite/pdf/res/2005/res358.pdf>. Acesso em: 17 maio 2012.

_. Resolução $\mathbf{n}^{0}$ 038, de 16 de julho de 2009. 2009c. Disponível em: <http://www.fnde.gov.br/pnae/legislacao>. Acesso em: 25 mar. 2012.

Resolução/CD/ FNDE no 4, de 9 de fevereiro de 2011. Estabelece os critérios de implementação e execução do Programa Nacional de Formação Continuada a Distância nas Ações do FNDE - Formação pela Escola, a partir do exercício de 2011.2011a. Disponível em: <http://www.fnde.gov.br/fnde/legislacao/resolucoes/item/3427-resolu\%C3\%A7\%C3\%A3o-cd-fnden\%C2\%BA-4-de-9-de-fevereiro-de-2011>. Acesso em: 25 mar. 2012.

CONSELHO NACIONAL DE SEGURANÇA ALIMENTAR. I Conferência Nacional de Segurança Alimentar. Relatório final. Brasília: CONSEA; 1995.

COSTA, Frederico; CASTANHAR, José. Avaliação de Programas Públicos: desafios conceituais e metodológicos. Revista de Administração Pública, Rio de Janeiro, v. 37, n. 5, set./out., 2003.

CUNHA, Carla Giane Soares da. Avaliação de Políticas Públicas e Programas Governamentais: tendências recentes e experiências no Brasil. São Paulo: [s.n], 2006.

CURY, Carlos Roberto Jamil. Educação e contradição: elementos metodológicos para uma teoria crítica do fenômeno educativo. São Paulo: Cortez Autores Associados, 1985.

DALBEN, Ângela Imaculada Loureiro de Freitas. Conselhos de Classe e Avaliação - Perspectivas na gestão pedagógica da escola. Campinas-SP, Papirus, 2004.

FRIGOTTO, Gaudêncio. O enfoque da dialética materialista histórica na pesquisa educacional. In: FAZENDA, Ivani (Org.) Metodologia da pesquisa educacional. São Paulo: Cortez, 2010.

INSTITUTO BRASILEIRO DE GEOGRAFIA E ESTATÍSTICA. Pesquisas sobre o desenvolvimento da população do Brasil e estudos posteriores do Laboratório de estatística. Rio de Janeiro: IBGE, 1951.

Sinopse do Censo Demográfico 2010. Rio de Janeiro: IBGE, 2011.

Pesquisa Nacional de Amostra de Domicílios. Síntese de Indicadores 2009. Rio de Janeiro, 2009, 261p. Disponível em Acesso em 11 jun.2012.

NIEBUHR, José de Menezes. Pregão Presencial e Eletrônico. Curitiba: Zênite Editora, 2008.

ORGANIZAÇÃO DAS NAÇÕES UNIDAS. Declaração Universal de Direitos Humanos. 1948. Disponível em: <http://www.unhchr.ch/udhr/lang/por.htm>. Acesso em: 24 mar. 2012

RODRÍGUEZ, Margarita Victoria. Políticas públicas e educação: a descentralização dos sistemas nacionais de ensino, análise e perspectivas. In: BITTAR, Mariluce; OLIVEIRA, João Ferreira de (Org.). Gestão e Políticas da Educação. Rio de Janeiro: DP\&A, 2004.

RUA, Maria das Graças. Avaliação de políticas, programas e projetos: notas introdutórias. São Paulo: [s.n.], 2003.

SANDER, Benno. Gestão da Educação na América Latina. Campinas, SP: Autores Associados, 1995.

SCHERER-WARREN, Ilse. Das Mobilizações às redes de movimentos sociais. Sociedade e Estado, Brasília, v. 21, n.1, p. 109-130, jan./abr. 2006. 
UCHÔA, José Renato. ABC do Direito Municipal. Rio de Janeiro: Ed. Forense, 1984.

VASCONCELOS, Francisco de Assis Guedes de. Combate à fome no Brasil: uma análise histórica de Vargas a Lula. Rev. Nutr., v. 18, n. 4, p. 439-457, 2005. ISSN 1415-5273

VIEIRA, Evaldo A. Estado e miséria social no Brasil: de Getúlio a Geisel. São Paulo: Cortez, 1995.

A política e as bases do direito educacional. Cadernos Cedes, ano XXI, n ${ }^{\circ}$ 55, novembro/2001. YANNOULAS, Silvia Cristina; ASSIS, Samuel Gabriel; FERREIRA, Kaline Monteiro. Educação e Pobreza: limiares de um campo em (re) definição. Revista Brasileira de Educação, Brasília, v. 17 n. 50, maio-ago. 2012

\section{Como citar este artigo (Formato ABNT):}

SALES, Rosana Maria Lima Albuquerque; Fnego, Graciela. Fiscalização dos Recursos da Merenda Escolar nas Escolas Públicas do Município de Satuba em Alagoas, desde o inicio até 2016. Id on Line Rev.Mult. Psic., 2018, vol.12, n.41, p.937-960. ISSN: 1981-1179.

Recebido: 25/07/2018.

Aceito: $27 / 07 / 2018$ 